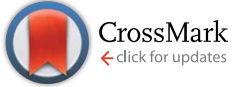

Cite this: RSC Adv., 2017, 7, 6753

Received 31st October 2016 Accepted 29th December 2016

DOI: $10.1039 / c 6 r a 26060 h$

www.rsc.org/advances

\section{Modification of a SLA titanium surface with calcium-containing nanosheets and its effects on osteoblast behavior}

\author{
Shui-yi Shao, $\uparrow^{\mathrm{ab}}$ Pan-pan Ming,,$^{\mathrm{ab}}$ Jing Quu, ${ }^{\star a b}$ Ying-juan Yu, ${ }^{\mathrm{ab}} \mathrm{Jie}^{\mathrm{a}}$ Yang, ${ }^{\mathrm{ab}}$ \\ Jia-xi Chen ${ }^{\mathrm{ab}}$ and Chun-bo Tang ${ }^{\mathrm{ab}}$
}

Objective: The aim of this study was to present a procedure to prepare a calcium-containing nanosheetsmodified sandblasted and acid etched (SLA) titanium surface and explore its effects on osteoblast behavior. Materials and methods: Through hydrothermal treatment with a mixed solution of $\mathrm{Ca}(\mathrm{OH})_{2}$ and $\mathrm{H}_{2} \mathrm{O}_{2}$, calcium-containing nanosheets were synthesized on a pretreated SLA titanium substrate. Different ratios of $\mathrm{Ca}(\mathrm{OH})_{2}$ to $\mathrm{H}_{2} \mathrm{O}_{2}$ in the mixed solution diversified the calcium-containing nanosheets-modified SLA titanium surfaces. Samples of two experimental groups (Ti-SLA-1/1 and Ti-SLA-5/1) were prepared with different mixed solutions, in which the ratios of $\mathrm{Ca}(\mathrm{OH})_{2}$ to $\mathrm{H}_{2} \mathrm{O}_{2}$ were $1: 1$ and $5: 1$, respectively. Physical properties, including surface topography, elemental composition, wettability, surface roughness, adhesion strength of coatings, and calcium release, were observed and measured. Assays of adhesion, spreading, proliferation, and differentiation of MC3T3-E1 cells, an osteoblast-like cell line, on the samples were investigated. Results: Two modified titanium surfaces were successfully prepared and appeared as calciumcontaining nanosheet-like structures, which revealed excellent superhydrophilicity and could release $\mathrm{Ca}^{2+}$ ions into phosphate buffer saline in a sustained manner. In addition, the modified titanium surfaces have satisfactory surface roughness and coating adhesion. The results of the in vitro study showed that the two modified titanium surfaces, especially the Ti-SLA-5/1 surface, exhibited satisfactory osteocompatibility and upregulated the cell adhesion, spreading, proliferation, and differentiation abilities as compared to the control SLA titanium surface. Conclusions: The modified nanosheet-like titanium surfaces demonstrated the ability to improve osteoblast behavior and exhibited the potential to improve bone-titanium integration.

\section{Introduction}

Since the discovery of wonderful biocompatibility and excellent mechanical strength of titanium and its alloys, they have been widely used for oral implants. However, patients, especially with underlying diseases, are still beset by the long osseointegration process of traditional oral implants. ${ }^{1-3}$ When an oral implant is inserted into the bone, stem cells initially adhere to the implant surface, which, in turn, plays an importance role in facilitating differentiation of cells along the osteoblast line to improve osseointegration., ${ }^{\mathbf{4 5}}$ Thus, a rapidly established, strong, and long lasting bond at the implant-bone interface is essential for the successful clinical application of oral implants. ${ }^{\mathbf{1}}$ This primarily depends on the characteristics of the implant surface.

\footnotetext{
${ }^{a}$ Department of Oral Implantology, Affiliated Hospital of Stomatology, Nanjing Medical University, Nanjing, 210029, P. R. China

${ }^{b}$ Jiangsu Key Laboratory of Oral Disease, Nanjing Medical University, Nanjing, 210029, P. R. China. E-mail: qiujing@njmu.edu.cn; Tel: +86 2585031834

$\dagger$ These authors contributed equally to this work.
}

Over the years, titanium surfaces have been constantly modified and optimized to improve osseointegration for oral implants. Sandblasting and acid etching (SLA), the most commonly used technique, can generate a hierarchical microstructured titanium surface, which has been proven in a large number of clinical studies to be efficacious for enhancing bone formation. ${ }^{6-8}$ Nowadays, as a mature surface modification for titanium, SLA has been used for a number of famous implant systems, such as Straumann, Bego, and Ankylos. Recently, nanostructure designs, which have an advantageous high surface-to-volume ratio and excellent absorbability, have become of particular interest due to their favorable biofunctionalization. ${ }^{9}$ The nanostructured surfaces have the potential to elicit additional gratifying biological effects on stem cells. In addition, the nanostructure dimension may play an important role in dictating the fate of the stem cells. It has been found that the adhesion and differentiation abilities of BMMSCs (bone marrow mesenchymal stem cells) on $\mathrm{TiO}_{2}$ nanotubes can be solely altered by adjusting the nanotube dimension. ${ }^{10}$ From the in vivo study, a significant enhancement in bone formation was detected on the titanium implant surface 
modified by $60 \mathrm{~nm}$ semi-spheres on the $28^{\text {th }}$ day after the implant insertion. ${ }^{\mathbf{1 1}}$

Surface chemistry also plays a vital role in the regulation of interactions between cells and biomaterials. ${ }^{\mathbf{1 2 - 1 6}}$ Calcium $(\mathrm{Ca})$, the principal component of bone, has received extensive attention in the field of titanium surface modification. ${ }^{15,17}$ It has been found that a calcium plasma implanted titanium surface was suitable for adhesion, spreading, and proliferation of osteoblasts. ${ }^{18-20}$ The calcium-incorporated titanium surface could upregulate the expressions of bone-related genes. ${ }^{21}$ Several studies have demonstrated that a Ca-rich layer on the titanium surface has the ability to accelerate the osseointegration process at both cellular and histological levels. $^{22-24}$

To date, various modification techniques, including plasma spraying, ${ }^{25,26}$ physical vapor deposition, ${ }^{27,28}$ chemical treatments, ${ }^{9,29}$ anodic oxidation, ${ }^{30,31}$ micro-arc oxidation, ${ }^{22}$ and calcium plasma immersion ion implantation, have been developed to prepare micro/nanostructures-modified or calcium-containing titanium surfaces. ${ }^{1,23}$ However, it is difficult to form micro/ nanostructures and directly incorporate calcium onto the titanium surface during an identical modification process. To the best of our knowledge, studies on the surface modification of titanium with calcium-containing nanosheets have not been reported to date. In this study, a convenient modification technique has been reported for the preparation of a calciumcontaining nanosheets-modified SLA titanium surface via a one-step treatment. Compared to other chemical treatments, this modification technique was convenient and synthesized nanosheets at the same time as incorporating calcium on the SLA titanium surface. The physical property of this novel modified titanium surface and its effects on cells were investigated. We hope that the results of this study would be valuable reference for studies based on cell-biomaterial interactions and oral implant surface modification designs.

\section{Materials and methods}

\section{Sample preparation}

Commercially pure titanium (99.5 wt\% purity, Alfa Aesar, USA) samples were prepared. Samples were sandblasted and ultrasonically cleaned with ethanol and distilled water. Subsequently, the SLA titanium surfaces were obtained by etching with a solution containing $\mathrm{HF} / \mathrm{HNO}_{3}$ (room temperature, $10 \mathrm{~min}$ ), and then with a solution containing $\mathrm{HCl} / \mathrm{H}_{2} \mathrm{SO}_{4}\left(80{ }^{\circ} \mathrm{C}\right.$ in a water bath, 30 min). Samples were dried in an oven at $50{ }^{\circ} \mathrm{C} .{ }^{13}$ The obtained samples were denoted as Ti-SLA samples and used as the control group. After this, Ti-SLA samples were immersed in a solution containing $\mathrm{Ca}(\mathrm{OH})_{2} / \mathrm{H}_{2} \mathrm{O}_{2}$ and the mixed solution was placed in a water bath at $70{ }^{\circ} \mathrm{C}$ for 12 hours. Different ratios of $\mathrm{Ca}(\mathrm{OH})_{2}$ to $\mathrm{H}_{2} \mathrm{O}_{2}$ in the mixed solution diversified the modified titanium surfaces. Samples of two experimental groups (Ti-SLA-1/1 and TiSLA-5/1) were prepared with different mixed solutions, in which the ratios of $\mathrm{Ca}(\mathrm{OH})_{2}$ to $\mathrm{H}_{2} \mathrm{O}_{2}$ were $1: 1$ and $5: 1$, respectively. The hydrothermal products were rinsed with distilled water, dried in an ambient atmosphere, and calcined at $450{ }^{\circ} \mathrm{C}$ for 1 hour.

\section{Surface characterization}

The surface morphologies of the Ti-SLA, Ti-SLA-1/1, and Ti-SLA5/1 samples were observed using field emission scanning electron microscopy (SEM, 1530VP, LEO, Germany). The surface elemental compositions of different samples were determined using an energy-dispersive X-ray spectrometer (EDX, INCA300, Oxford, UK). A conductive coating of Aurum (Au) was deposited on each sample surface for SEM observation. Carbon (C) was presented as a surface contaminant. ${ }^{32}$ Therefore, Au from the conductive coating and $\mathrm{C}$ from the surface contaminants were eliminated for determining the surface elemental compositions by EDX. The bonding states and depth profiles of the surface constituents were identified by X-ray photoelectron spectroscopy (XPS, Thermo Scientific Escalab 250Xi, USA) using an $\mathrm{Al} \mathrm{K \alpha}$ radiation at $150 \mathrm{~W}$ with argon sputtering etching. Survey and high-resolution spectra were obtained. Reference binding energy of each element was obtained from the National Institute of Standards and Technology XPS Online Database (http:// srdata.nist.gov/xps/). Spectra were calibrated by adjusting the binding energy of the $\mathrm{C} 1 \mathrm{~s}$ signal to $284.8 \mathrm{eV}$. The surface roughness of different samples was determined using a surface roughness tester (TR200, Detect Kaiyan, China) with a tracing length of $1 \mathrm{~mm}$ and a cut-off of $0.25 \mathrm{~mm}$. Five tracings were made on each sample. ${ }^{33}$ The adhesion strength of the nanosheets was measured using an electronic universal material testing machine (R3365, USA) at a constant crosshead speed of 1 $\mathrm{mm} \min ^{-1}$. The test assembly was composed of the experimental sample bonded to a titanium base with an overlapped area of $19.625 \mathrm{~mm}^{2}$ (5 $\mathrm{mm}$ diameter). Two parts of the test assembly were bonded together by an epoxy glue (9005, LEAFTOP, China) and cured at room temperature for $24 \mathrm{~h}$. The shear strength was calculated as the load at failure divided by the coated area. ${ }^{34,35}$ Five samples for each group were tested.

\section{$\mathrm{Ca}^{2+}$ ion release assay}

Ti-SLA-1/1 and Ti-SLA-5/1 samples (18 $\mathrm{mm}$ diameter and 0.25 $\mathrm{mm}$ thickness) were soaked in 12-well plates with $1 \mathrm{~mL}$ of phosphate-buffered saline (PBS) per well at $37^{\circ} \mathrm{C}$ for $10 \mathrm{~min}$, $1 \mathrm{~h}, 2 \mathrm{~h}, 4 \mathrm{~h}, 1$ day, 4 days, and 7 days. The weight-to-volume ratio of sample and PBS were $0.4 \mathrm{~g} \mathrm{~mL}^{-1} \cdot \mathrm{Ca}^{2+}$ ion released into the PBS solution was quantified using the Quantichrom (BioAssay System, Hayward, CA, USA) colorimetric assay kit. ${ }^{\mathbf{1 5}}$ The absorbances were measured using a microplate reader (Spectramax190, MD, USA) at $612 \mathrm{~nm}$ wavelength.

\section{Contact angle measurement}

The surface wettabilities of Ti-SLA, Ti-SLA-1/1, and Ti-SLA-5/1 samples were evaluated from contact angle measurements using an Automatic Contact Angle Meter Model SL200B (Solon, Shanghai, China) in an ambient environment using $2 \mu \mathrm{L}$ sessile distilled water droplets.

\section{Cell culture}

MC3T3-E1 cells, an osteoblast-like cell line, could act as an in vitro model of osteoblast development. ${ }^{36}$ In addition, the 
MC3T3-E1 cells were extensively used for evaluating cell responses, such as attachment, proliferation, calcification, and gene expressions, according to the previous studies. ${ }^{37-39}$ Thus, MC3T3-E1 cells were chosen for this investigation. The cells were purchased from the Chinese Academy of Sciences Cell Bank (Shanghai, China). The cells were maintained in $\alpha$ Minimum Essential Medium ( $\alpha$-MEM, Gibco, USA) containing $10 \%$ fetal bovine serum (FBS, Gibco, USA) and 1\% penicillin/ streptomycin (Gibco, USA) in a humidified atmosphere of $5 \%$ $\mathrm{CO}_{2}$ and $95 \%$ air at $37^{\circ} \mathrm{C}$. The medium was changed every two days. Cells were passaged at a ratio of $1: 4$ every 3-4 days when covering $80 \%$ area of the cell culture bottle.

\section{Cell adhesion and spreading assay}

For the cell adhesion and spreading assay, MC3T3-E1 cells $(5 \times$ $10^{3}$ cells per well) were seeded on Ti-SLA, Ti-SLA-1/1, and Ti-SLA$5 / 1$ samples. After culturing the cells for 8 hours, each sample was rinsed with PBS, and then fixed with $4 \%$ paraformaldehyde in PBS at room temperature for 10 minutes. Afterwards, each sample was stained with Rhodamine Phalloidin (Cytoskeleton, USA) at room temperature in the dark for 30 minutes, and then with $\quad 4^{\prime}, 6^{\prime}$-diamidino-2-phenylindole (DAPI) (Beyotime, Shanghai, China) for 30 seconds. The cells in five random fields on each sample were observed using a laser scanning confocal microscope (LSM710, Zeiss, GER). The cell number on each sample was counted at $200 \times$ magnification and the cell morphology was observed at $400 \times$ magnification.

\section{Cell proliferation assay}

For the cell proliferation assay, MC3T3-E1 cells $\left(2 \times 10^{3}\right.$ cells per well) were seeded on Ti-SLA, Ti-SLA-1/1, and Ti-SLA-5/1 samples. After culturing the cells for 1,3 , and 6 days, the media were removed and a new solution containing $10 \mu \mathrm{L}$ of CCK-8 solution (Beyotime, China) and $100 \mu \mathrm{L}$ of culture medium was added in each well, and then incubated for 2 hours. After this, the absorbances of the incubated solutions were measured by a microplate reader (Spectramax190, MD, USA) at $450 \mathrm{~nm}$ wavelength.

\section{Alkaline phosphatase (ALP) activity assay}

For the ALP activity assay, MC3T3-E1 cells $\left(5 \times 10^{4}\right.$ cells per well) were seeded on Ti-SLA, Ti-SLA-1/1, and Ti-SLA-5/1 samples. After culturing the cells for 7 and 14 days, each sample was rinsed with PBS, and then the cells on different samples were lysed in radioimmunoprecipitation assay (RIPA) buffer (LEAGENE, Beijing, China) at $4{ }^{\circ} \mathrm{C}$ for 30 minutes. The lysates were centrifuged at $12000 \mathrm{rpm}$ at $4{ }^{\circ} \mathrm{C}$ for 10 minutes, and then the liquid supernatants were collected. The ALP activity was acquired using an AKP assay kit (Jiancheng Bioengineering Institute, China) and the total protein content was acquired using a BCA protein assay kit (KeyGEN BioTECH, China).

\section{Real-time quantitative PCR}

The expression levels of osteogenic-related genes, Runx2, OPN, and OCN, on different surfaces were measured using real-time
Table 1 Primer sequences of target genes for real-time PCR used in this study

\begin{tabular}{lll}
\hline Gene & Primer sequence (F: forward; R: reverse) & $\begin{array}{l}\text { Product } \\
\text { size (bp) }\end{array}$ \\
\hline Runx2 & $\begin{array}{l}\text { F: CCGAAATGCCTCCGCTGTTATG } \\
\text { R: TCTGTCTGTGCCTTCTTGGTTCC }\end{array}$ & 194 \\
OPN & $\begin{array}{l}\text { F: GCAGAGAGCGAGGATTCTGT } \\
\text { R: TGTAGGGACGATTGGAGTGA }\end{array}$ & 120 \\
OCN & $\begin{array}{l}\text { F: CACCTAGCAGACACCATGAGGAC } \\
\text { R: GACTGAGGCTCCAAGGTAGCG }\end{array}$ & 180 \\
$\beta-$ & $\begin{array}{l}\text { F: GTGCTATGTTGCTCTAGACTTCG } \\
\text { Actin }\end{array}$ & R: ATGCCACAGGATTCCATACC \\
\end{tabular}

quantitative PCR. MC3T3-E1 cells were seeded on Ti-SLA, TiSLA- $1 / 1$, and Ti-SLA-5/1 samples at a density of $1 \times 10^{5}$ cells per well, cultured for 7 and 14 days, and then harvested using Trizol reagent (Invitrogen, USA) to extract the total RNA. The RNA was reverse transcribed into complementary DNA (cDNA) using PrimeScript RT Master mix (Takara, Kusatsu, Japan) and real-time PCR was performed via a ABI 7300 real-time PCR system (Applied Biosystems, USA) using SYBR Premix Ex Taq (Takara, Kusatsu, Japan). The primer sequences of the targeted genes are listed in Table 1. Real-time PCR was performed in triplicate for each group and the expression levels of the target genes were normalized to that of the $\beta$-actin gene.

\section{Western blotting}

The protein expressions of Runx2, OPN, and OCN on different surfaces were examined by western blotting. After MC3T3-E1 cells $\left(2 \times 10^{5}\right.$ cells per well $)$ were cultured on Ti-SLA, Ti-SLA- $1 /$ 1 , and Ti-SLA-5/1 samples for 7 and 14 days, cells were rinsed with cold PBS and then harvested by lysis in RIPA buffer. Total proteins were determined using a BCA protein assay kit (KeyGEN BioTECH, Nanjing, China). Protein extract samples (20 $\mu \mathrm{g})$ were separated using SDS-PAGE, and then transferred to polyvinylidene fluoride (PVDF) membranes (Millipore, USA). After blocking with $5 \%$ skim milk for $1 \mathrm{~h}$, the membranes were incubated with different primary antibodies against Runx2 (12556, CST, USA), OPN (ab8448, Abcam, USA), OCN (ab93876, Abcam, USA), and $\beta$-actin (BM0627, Boster, China) overnight at $4{ }^{\circ} \mathrm{C}$. These membranes were then incubated for $2 \mathrm{~h}$ with secondary antibodies (ZB-2301, Goat anti-Rabbit IgG, ZSGBBIO, China; AP124P, Goat anti-Mouse IgG, Millipore, USA). Immobilon western chemiluminescent HRP substrate (Millipore, USA) was used to detect the protein signals. The protein expressions were determined relative to those of $\beta$-actin that was used as an internal control.

\section{Statistical analysis}

The acquired data were analyzed using SPSS 22.0 (SPSS Inc, Chicago, IL, USA) via one-way analysis of variance. $P<0.05$ was considered statistically significant. 

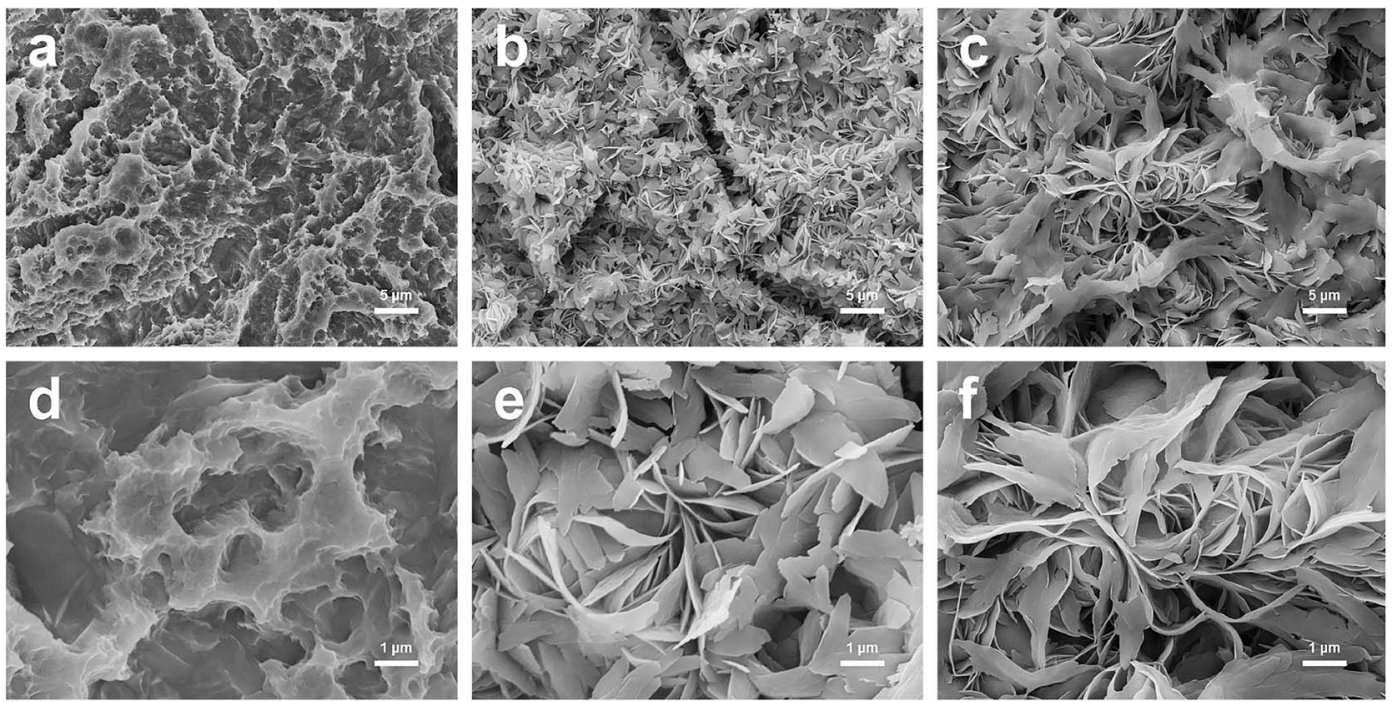

Fig. 1 Scanning electron microscopy images of three surfaces at different magnifications. Upper panel ((a): Ti-SLA; (b) Ti-SLA-1/1; and (c) TiSLA-5/1) displays the images at 2000x magnification. Lower panel ((d): Ti-SLA; (e) Ti-SLA-1/1; and (f) Ti-SLA-5/1) displays the images at 10 000x magnification.

\section{Results}

\section{Surface structure and composition analysis}

SEM images of Ti-SLA, Ti-SLA-1/1, and Ti-SLA-5/1 samples are shown in Fig. 1. Under lower magnification, the Ti-SLA sample appeared as a hierarchical microscale structure (Fig. 1a). After 12 hours of hydrothermal treatment and subsequent 1 hour calcination, both surfaces of Ti-SLA-1/1 and Ti-SLA-5/1 samples appeared as nanosheet-like structures (Fig. 1b and c). Under higher magnification, round micro-pits with sharp edges were observed on the Ti-SLA surface (Fig. 1d), and the nanosheetstructures on the Ti-SLA-1/1 and Ti-SLA-5/1 surfaces became overlapped and entangled, forming interconnected networks (Fig. 1e and f). The thickness of the nanosheets was approximately 20-60 nm. Comparing with the Ti-SLA-1/1 surface, the Ti-SLA-5/1 surface exhibited a more apparent nanosheet structure.

XPS survey spectra acquired for different surfaces are displayed in Fig. 2a. Titanium (Ti), oxygen (O), and calcium (Ca) are shown to be present on both Ti-SLA-1/1 and Ti-SLA-5/1 surfaces. There was no calcium on the control Ti-SLA surface.
Adventitious carbon (C) peaks are most likely present due to contamination. The XPS high-resolution spectra of $\mathrm{Ca} 2 \mathrm{p}$ on both Ti-SLA-5/1 and Ti-SLA-1/1 surfaces are displayed in Fig. 2b and c. The Ca 2 p spectra exhibited peaks at about $347.3 \mathrm{eV}(2 \mathrm{p} 3 /$ 2) and $350.9 \mathrm{eV}(2 \mathrm{p} 1 / 2)$, indicating the existence of calcium oxide $(\mathrm{CaO})$. Moreover, it could be observed that the intensities of the $\mathrm{Ca} 2 \mathrm{p}$ peaks on the two surfaces remained unchanged with the increasing etching time.

As shown in Table 2, the EDX results demonstrated that Ti, $\mathrm{O}$, and $\mathrm{Ca}$ were detected on both Ti-SLA-1/1 and Ti-SLA-5/1 surfaces, whereas there was no calcium on the control Ti-SLA surface. Approximately $2.25 \pm 0.15$ at $\%$ and $4.45 \pm 0.52$ at $\%$ of calcium was detected on the Ti-SLA-1/1 and Ti-SLA-5/1 surfaces, respectively.

Table 3 shows the results of surface roughness and adhesion strength of the coatings. From the results, though not significant, Ti-SLA-1/1 and Ti-SLA-5/1 surfaces revealed slightly higher surface roughness than the control Ti-SLA surface. There was no statistical difference among the adhesion strengths of the three surfaces, indicating satisfactory coating adhesion strengths of Ti-SLA-1/1 and Ti-SLA-5/1 surfaces.
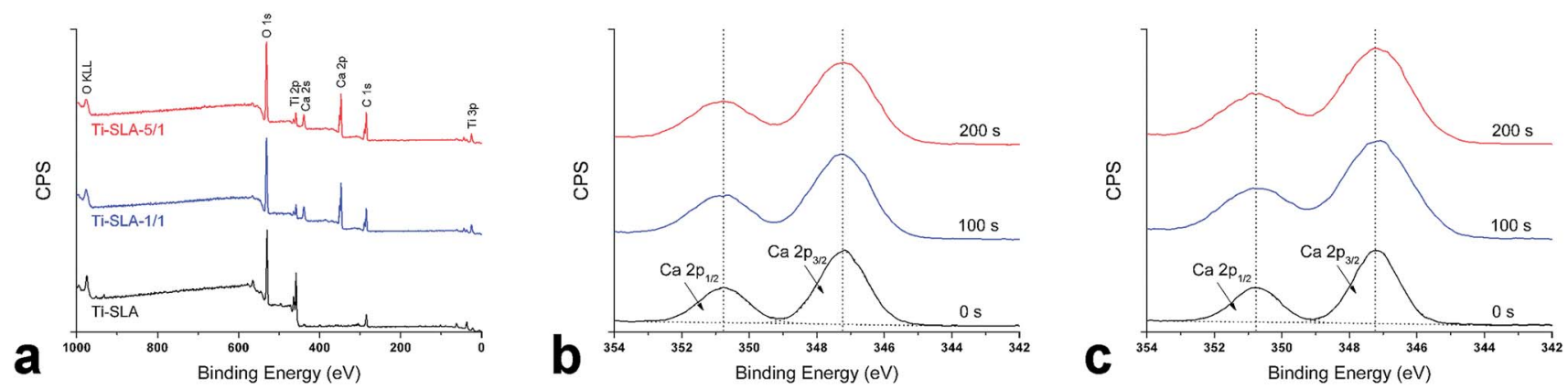

Fig. 2 XPS spectra of samples: (a) survey spectra of three surfaces; (b) high-resolution spectra of Ca $2 p$ on the Ti-SLA-1/1 surface as a function of argon sputtering etching time; and (c) high-resolution spectra of Ca $2 p$ on the Ti-SLA-5/1 surface as a function of argon sputtering etching time. 
Table 2 Surface elemental compositions of different samples determined by EDX (at\%, $n=4)$

\begin{tabular}{llll}
\hline Group & Titanium (Ti) & Oxygen $(\mathrm{O})$ & Calcium $(\mathrm{Ca})$ \\
\hline Ti-SLA & $33.33 \pm 0$ & $66.67 \pm 0$ & - \\
Ti-SLA-1/1 & $31.84 \pm 0.10$ & $65.92 \pm 0.05$ & $2.25 \pm 0.15$ \\
Ti-SLA-5/1 & $30.37 \pm 0.35$ & $65.19 \pm 0.17$ & $4.45 \pm 0.52$
\end{tabular}

Table $3 R_{\mathrm{a}}$ values of surface roughness and adhesion strengths of three groups $(n=5)$

\begin{tabular}{lll}
\hline Group & $R_{\mathrm{a}}(\mu \mathrm{M})$ & Adhesion strength $(\mathrm{MPa})$ \\
\hline Ti-SLA & $1.62 \pm 0.16$ & $11.57 \pm 2.63$ \\
Ti-SLA-1/1 & $1.66 \pm 0.12$ & $12.62 \pm 3.09$ \\
Ti-SLA-5/1 & $1.68 \pm 0.13$ & $14.12 \pm 2.98$ \\
\hline
\end{tabular}

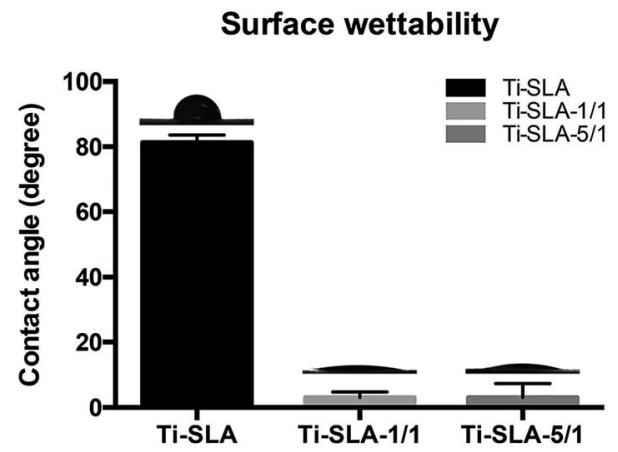

Fig. 3 The contact angles of different surfaces. Contact angles of TiSLA, Ti-SLA-1/1, and Ti-SLA-5/1 surfaces are displayed. Ti-SLA-5/1 and Ti-SLA-1/1 surfaces showed superhydrophilicity compared to the TiSLA surface.

\section{Surface contact angle}

The surface contact angles are shown in Fig. 3. The Ti-SLA surface showed hydrophobicity with a contact angle of $81.28^{\circ}$. Both TiSLA-1/1 and Ti-SLA-5/1 surfaces showed superhydrophilicity with contact angles of $3.05^{\circ}$ and $3.17^{\circ}$, respectively, which were significantly better than that of the Ti-SLA surface. Moreover, the contact angles of hydrothermally treated samples (Ti-SLA-1/1 and Ti-SLA-5/1) did not significantly change on altering the ratio of $\mathrm{Ca}(\mathrm{OH})_{2}$ to $\mathrm{H}_{2} \mathrm{O}_{2}$ in the mixed solution.

\section{$\mathrm{Ca}^{2+}$ ion release}

Fig. 4 shows the concentrations of $\mathrm{Ca}$ ions released from different samples into PBS. It was found that Ti-SLA-1/1 and TiSLA-5/1 samples released $1.29 \pm 0.23 \mathrm{ppm}$ and $1.70 \pm 0.14 \mathrm{ppm}$ of $\mathrm{Ca}^{2+}$ ions within $24 \mathrm{~h}$, respectively. After the burst release in the initial $24 \mathrm{~h}$ period, both concentrations of $\mathrm{Ca}^{2+}$ ion released from Ti-SLA-1/1 and Ti-SLA-5/1 samples nearly reached their own peaks. In addition, the average value of $\mathrm{Ca}^{2+}$ ion released from the Ti-SLA-5/1 sample was higher than that released from the Ti-SLA-1/1 sample.

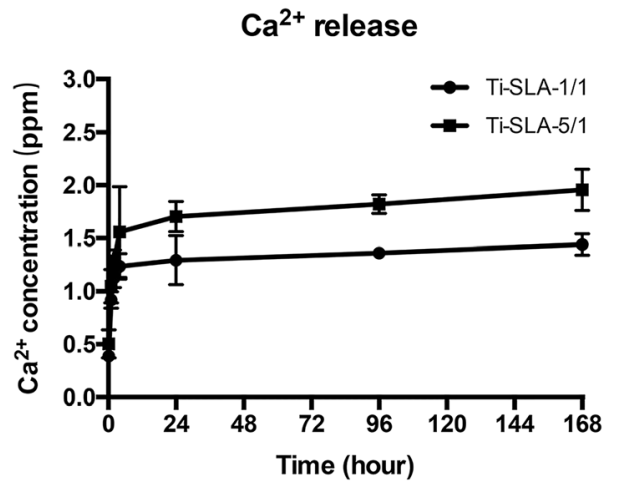

Fig. 4 Concentrations of $\mathrm{Ca}^{2+}$ ions released from Ti-SLA-1/1 and Ti-SLA5/1 samples into PBS after 10 min, 1 h, 2 h, 4 h, 1 day, 4 days, and 7 days.

\section{Cell adhesion and spreading}

Fig. 5 shows the number of remaining MC3T3-E1 cells attached to the three substrates after culturing for 8 hours, and then rinsing with PBS. Measured by counting the cellular nuclei, the quantitative data of the three substrates revealed that there were significantly more adhered cells on the Ti-SLA- $1 / 1$ and Ti-SLA-5/ 1 surfaces than those on the Ti-SLA surface $(P<0.05)$. After culturing for 8 hours, differences in the cell morphology could be observed as well (Fig. 6). The cells spread more evenly across the Ti-SLA-1/1 and TiSLA-5/1 surfaces and extended more pseudopodia compared with those on the Ti-SLA surface. There was no significant difference in the cell spreading between Ti-SLA-1/1 and Ti-SLA-5/1 surfaces.

\section{Cell proliferation}

Cell proliferation, as measured by the CCK- 8 assay, is shown in Fig. 7. As time went on, the MC3T3-E1 cells proliferated on all the samples, indicating excellent cell viabilities for the three titanium surfaces. After hydrothermal treatments, statistically significant increase in the cell proliferation could be observed on the Ti-SLA-1/1 and Ti-SLA-5/1 surfaces compared to the TiSLA surface after culturing for 6 days. The results revealed that both Ti-SLA-1/1 and Ti-SLA-5/1 surfaces offered more favorable environments for cell proliferation.

\section{ALP activity}

Fig. 8 shows the results of the ALP assay. The ALP activity of MC3T3-E1 cells on all samples increased as the culturing time increased. After culturing for 7 days, both Ti-SLA-1/1 and Ti-SLA5/1 surfaces exhibited significantly higher ALP activity than the Ti-SLA surface. After culturing for 14 days, the Ti-SLA-5/1 surface demonstrated the highest ALP activity, followed by the Ti-SLA-1/1 surface, and then the Ti-SLA surface.

\section{Real-time quantitative PCR analysis}

The selected osteogenic-related genes, including Runx2, OPN, and OCN, were analyzed via a real-time PCR quantitative technique. As shown in Fig. 9, the gene expression levels of MC3T3E1 cells on both nanosheets-modified titanium surfaces (TiSLA-1/1 and Ti-SLA-5/1) were up-regulated as compared to those of MC3T3-E1 cells on the control Ti-SLA surface after 

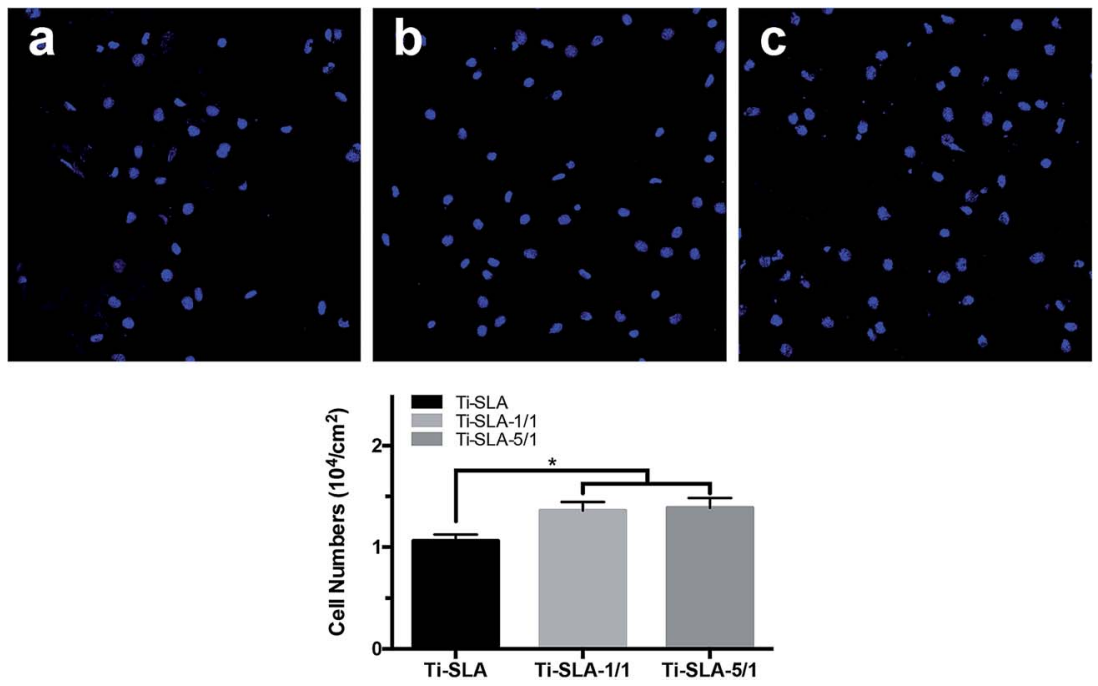

Fig. 5 Cell adhesion ability assay. Adhesion ability of MC3T3-E1 cells was analyzed by counting the stained nuclei with DAPI using a confocal laser scanning microscope (CLSM) after 8 hours of incubation. The upper panel shows the CLSM images of the cells on three substrates at $200 \times$ magnification. ((a) Ti-SLA; (b) Ti-SLA-1/1; and (c) Ti-SLA-5/1). The lower panel shows the statistical results for adhesive cell numbers. * indicate $P<$ 0.05 versus Ti-SLA surface.
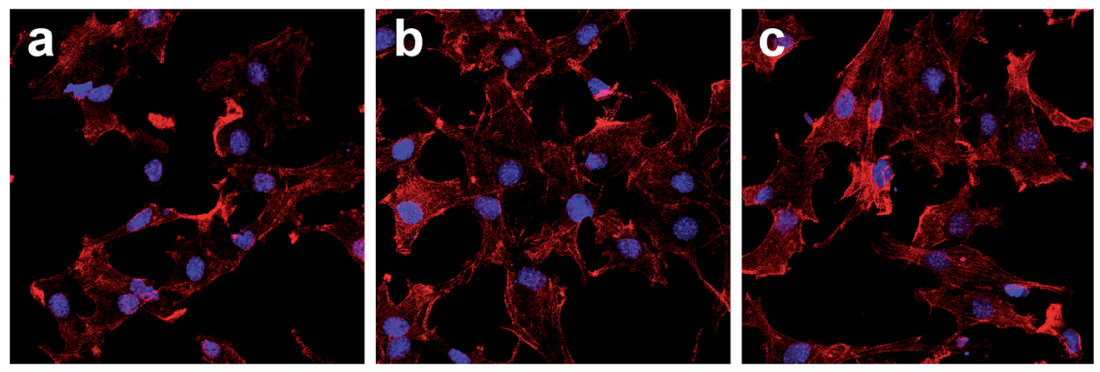

Fig. 6 Fluorescence images of MC3T3-E1 cells spread on three substrates after 8 h of incubation (magnification 400 ×). (a) Ti-SLA; (b) Ti-SLA-1/1; and (c) Ti-SLA-5/1.

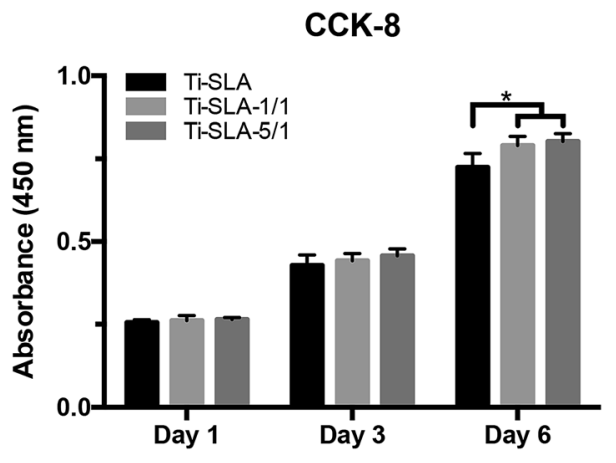

Fig. 7 After culturing for 1, 3, and 6 days, cell proliferation of MC3T3E1 cells adhered to Ti-SLA, Ti-SLA-1/1, and Ti-SLA-5/1 surfaces were analyzed by CCK- 8 assay. * indicate $P<0.05$ versus Ti-SLA surface.

culturing for 7 and 14 days. Moreover, the Ti-SLA-5/1 surface, which incorporated more calcium, induced the highest levels of Runx2, OPN, and OCN gene expressions.

\section{Western blotting analysis}

Western blotting analysis was performed to verify the osteogenic-related protein expression levels. As shown in Fig. 10, MC3T3-E1 cells on the two nanosheets-modified titanium surfaces (Ti-SLA-1/1 and Ti-SLA-5/1) showed higher protein expression levels of Runx2, OPN, and OCN than those

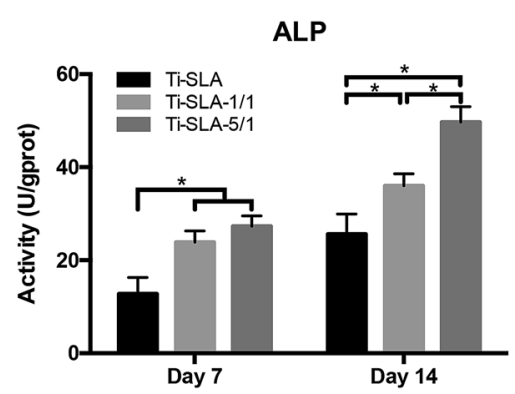

Fig. 8 The alkaline phosphatase (ALP) activity of the MC3T3-E1 cells on three substrates after culturing for 7 and 14 days. * indicate significant differences between different substrates $(P<0.05)$. 

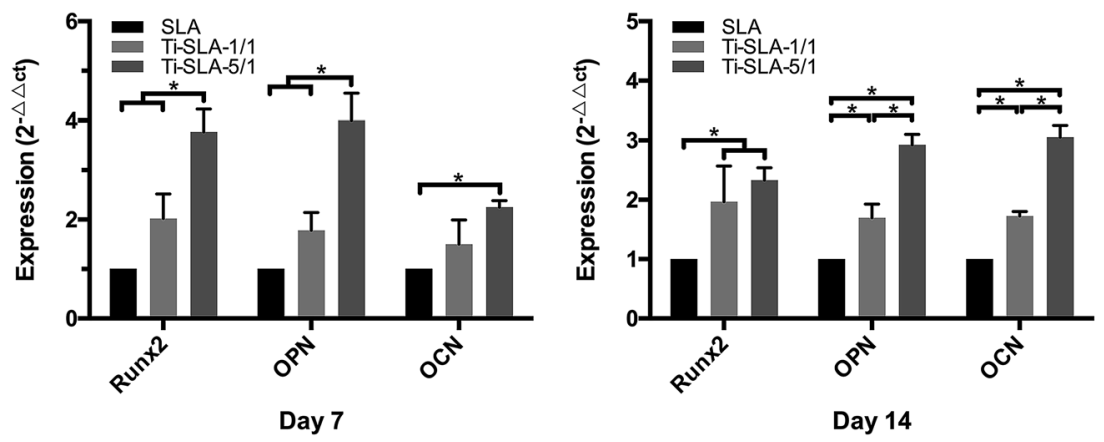

Fig. 9 After 7 and 14 days of incubation on three substrates, total mRNA of MC3T3-E1 cells were extracted and gene expressions of Runx2, OPN, and OCN were measured by real-time qPCR. Results are expressed as relative transcript levels to $\beta$-actin $(n=3)$. * indicate significant differences between different substrates $(P<0.05)$.

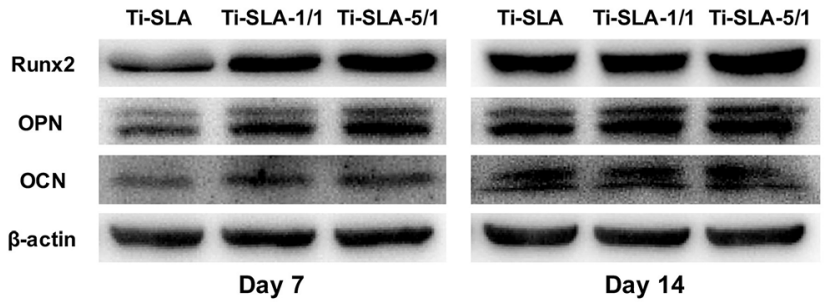

Fig. 10 Osteogenic-related protein expression levels of Runx2, OPN, and OCN of MC3T3-E1 cells on three substrates were detected by western blotting after culturing for 7 and 14 days.

on the control Ti-SLA surface after culturing for 7 and 14 days. An interesting finding was that MC3T3-E1 cells cultured on the Ti-SLA-5/1 surface expressed the highest protein levels of Runx2, OPN, and OCN gene expressions.

\section{Discussion}

A titanium surface was hydrothermally treated with a mixed solution of $\mathrm{Ca}(\mathrm{OH})_{2}$ and $\mathrm{H}_{2} \mathrm{O}_{2}$ in the present study, which provided a relatively convenient approach to fabricate calciumcontaining nanosheets on a SLA titanium surface. In previous studies, various methods have been used to prepare micro/ nano-topography or to incorporate calcium into the titanium surface. ${ }^{1,18,20}$ However, it is difficult to form micro/ nanostructures at the same time as incorporating calcium into the titanium surface during an identical modification process. In this study, a hydrothermal treatment was used to prepare calcium-containing nanosheets on the SLA titanium surface. Based on the different ratios of $\mathrm{Ca}(\mathrm{OH})_{2}$ to $\mathrm{H}_{2} \mathrm{O}_{2}(1: 1$ and $5: 1$ ) in the mixed solutions for treatments, two calciumcontaining nanosheets-modified SLA titanium surfaces (TiSLA-1/1 and Ti-SLA-5/1) were prepared. Due to the incorporated calcium and nanoscale thickness of the nanosheets, which might endow the modified surfaces with nanostructure properties, increased in vitro bioactivities of the two calciumcontaining nanosheets-modified surfaces were confirmed.

Through hydrothermal treatment with a mixed solution of $\mathrm{Ca}(\mathrm{OH})_{2}$ and $\mathrm{H}_{2} \mathrm{O}_{2}$, calcium-containing nanosheets were synthesized on a pretreated SLA titanium sample surface. The modified titanium surfaces were investigated via SEM, XPS, and EDX. From the results, Ti-SLA-1/1 and Ti-SLA-5/1 samples exhibited similar nanosheets topography with differences only in the structure scale and calcium content. As detected by XPS and EDX, surface elemental composition primarily consisted of titanium, oxygen, and calcium. Another study reported that size-controllable sawtooth-like $\mathrm{TiO}_{2}$ nanostructures could be prepared on titanium surfaces via hydrothermal treatment with a solution of $\mathrm{H}_{2} \mathrm{O}_{2}{ }^{9}$ It was also reported that nanometer-scale roughness could be formed on the titanium surface when titanium was exposed to strongly alkaline solutions with a high $\mathrm{pH}$ value. ${ }^{40}$ In this study, the addition of $\mathrm{Ca}(\mathrm{OH})_{2}$ in the $\mathrm{H}_{2} \mathrm{O}_{2}$ solution increased both the $\mathrm{pH}$ value and the calcium content. It seemed that $\mathrm{H}_{2} \mathrm{O}_{2}$ and $\mathrm{OH}^{-}$in the solution reacted with SLA titanium surface and $\mathrm{Ca}^{2+}$ was incorporated into the production for charge balance. Then, the calcium-containing nanosheets were synthesized on the SLA titanium surface.

The roughness of the implant surface was also a promoter for bone formation. ${ }^{41}$ As a mature surface modification for titanium, the SLA titanium surface has satisfactory surface roughness. The results showed that the modified titanium samples and SLA surfaces revealed similar surface roughness, which might contribute to cell adhesion. ${ }^{42}$ The result of shear strength showed that the coating of modified titanium surfaces exhibited satisfactory adhesion strength. From the results and other studies, ${ }^{9}$ it could be suggested that chemical bonding existed between the nanosheets and titanium surface.

From the contact angle results, the two calcium-containing nanosheets-modified SLA titanium surfaces exhibited superhydrophilicity, which was favorable for cell adhesion activity. ${ }^{43}$ The results of the $\mathrm{Ca}^{2+}$ ion release studies showed that $\mathrm{Ca}^{2+}$ ion rapidly released into PBS at the initial stage, and then its concentration maintained a relatively high level over time. Multitudinous studies have confirmed the potential of calcium to upregulate the bone-related genes expressions and elicit satisfactory biological effects. ${ }^{1,21-24}$ Moreover, other titanium surface properties, including microscale topography, nanostructures, and chemical composition, could influence the osteoblast behavior. ${ }^{4-46}$ Considering the abovementioned factors, we believe that calcium incorporated into the 
nanosheets might contribute to enhance the bioactivity of the modified titanium surfaces in the current study.

The cell adhesion and spreading results demonstrated that both calcium-containing nanosheets-modified SLA titanium surfaces promoted the early attachment and spreading of osteoblasts. The osteoblasts on the Ti-SLA- $1 / 1$ and Ti-SLA-5/1 surfaces extended more pseudopodia than those on the TiSLA surface. These findings are in agreement with those of previous studies. ${ }^{\mathbf{1 9 , 4 3}}$ It is well known that nanostructure and hydrophilicity are regarded as the promoting factors for cell adhesion., ${ }^{\mathbf{1 , 4 4 - 4 6}}$ The improvements in cell adhesion and spreading on the modified titanium surfaces should be attributed to their advantageous surface properties. Cell adhesion, which belongs to the first phase of cell/biomaterial interaction, plays an important role in regulating the cell proliferation. ${ }^{\mathbf{4 7 , 4 8}}$ In this work, MC3T3-E1 cells adhered to Ti-SLA-1/1 and Ti-SLA$5 / 1$ samples grew better than those on Ti-SLA samples after culturing for 6 days. Both increased initial number of adhesive cells and enhanced cell spreading on the titanium surfaces may have promoted the observed proliferation as well. ${ }^{47}$ Additionally, some studies have reported that calcium has beneficial effects on cell proliferation, ${ }^{\mathbf{1 , 4 5}}$ which is consistent with our results.

The osteogenic differentiation ability of MC3T3-E1 cells on three substrates were compared at both gene and protein levels. As significant osteogenic markers, Runx2, OPN, OCN, and ALP were selected to analyze the differentiation activities. ${ }^{49}$ Runx2, expressed in the early stage of osteogenic differentiation, is a vital transcription factor for osteoblast differentiation and bone formation. ${ }^{9}$ For osteogenic differentiation, OPN, extensively recognized as a mediate marker, is mainly associated with osteoblast maturation in the relatively early stage. ${ }^{9}$ As a late marker of osteogenic differentiation, OCN directly participates in the mineralization process. ${ }^{9}$ ALP is also a commonly employed marker for osteoblast differentiation at the early stage. ${ }^{\mathbf{1 2 5 0 , 5 1}}$ In this study, both quantitative PCR and western blotting analysis demonstrated that the two calcium-containing nanosheets-modified SLA titanium surfaces (Ti-SLA-1/1 and TiSLA-5/1) up-regulated the expressions of Runx2, OPN, and OCN compared to the control SLA titanium surface (Ti-SLA). Correspondingly, the ALP activity of the MC3T3-E1 cells cultured on the Ti-SLA-1/1 and Ti-SLA-5/1 surfaces were up-regulated. Furthermore, MC3T3-E1 cells on the Ti-SLA-5/1 surface, containing higher calcium, exhibited the highest expression levels among the three substrates. As responding to the calciumcontaining nanosheets-modified SLA titanium surfaces, the cell adhesion and osteogenic differentiation abilities were both enhanced. From the results, we believe that both the nanosheetlike structure and the incorporated calcium were the promoting factors for osteogenic ability. For cell adhesion, spreading and proliferation abilities, it seemed that nanosheets might be the more decisive factor. For cell differentiation abilities, the calcium content might be the more decisive factor. We believed that the adhering MC3T3-E1 cells were first exposed to more contact locations on the calcium-containing nanosheets, which are able to absorb more extracellular matrix proteins and release $\mathrm{Ca}^{2+}$ ion. Thus, the stimuli from the nanosheets, calcium, and extracellular matrix all promoted the bone formation.

In this study, SLA titanium surface, the most commonly used titanium surface for oral implants, was chosen as the precursor to prepare the novel titanium surface and as a control to evaluate the effects of the modification. Due to the different structures and chemical constituents, the two modified titanium surfaces exhibited better bioactivity than the unmodified SLA titanium surface. Furthermore, based on the abovementioned results, it is expected that the biofunctionalization differences between the two calcium-containing nanosheets-modified SLA titanium surfaces may be primarily caused by differences in their calcium content. The exact mechanism for the calciumcontaining nanosheets modification in regulating the bone formation process still requires further investigation.

\section{Conclusions}

A convenient technique to synthesize nanosheets and incorporate calcium into the SLA titanium surface at the same time has been employed in this study. Two types of calcium-containing nanosheet-like structures were prepared on the SLA titanium substrates. Compared with the control SLA titanium surface, MC3T3-E1 cells cultured on the two modified titanium surfaces exhibited enhanced adhesion, proliferation, and osteogenic differentiation abilities. The Ti-SLA-5/1 surface, containing more calcium content, elicited the most gratifying biological effects on the osteoblasts among the three substrates and suggested the potential for the induction of improved osseointegration.

\section{Acknowledgements}

This study was supported by the National Natural Science Foundation of China (Project Number: 81472928), the Natural Science Foundation of Jiangsu Province (Project Number: BK20130898), the Medical Science Foundation of Jiangsu Provincial Health Department (Project Number: H201641), the "Six Talent Peaks" Project in Jiangsu Province (Project Number: 2014-WSW-035), the Practice Innovation Training Program Project for the Jiangsu College Students (Project Number: 201310312020Z), and the Foundation of Priority Academic Program Development of Jiangsu Higher Education Institutions (Project Number: 2014-37).

\section{References}

1 M. Cheng, Y. Qiao, Q. Wang, G. Jin, H. Qin, Y. Zhao, X. Peng, X. Zhang and X. Liu, ACS Appl. Mater. Interfaces, 2015, 7, 13053-13061.

2 L. Jonásová, F. A. Müller, A. Helebrant, J. Strnad and P. Greil, Biomaterials, 2004, 25, 1187-1194.

3 G. Giro, L. Chambrone, A. Goldstein, J. A. Rodrigues, E. Zenóbio, M. Feres, L. C. Figueiredo, A. Cassoni and J. A. Shibli, World Journal of Orthopedics, 2015, 6, 311-315.

4 N. Wang, H. Li, W. Lü, J. Li, J. Wang, Z. Zhang and Y. Liu, Biomaterials, 2011, 32, 6900-6911. 
5 G. Mendonca, D. B. Mendonca, F. J. Aragao and L. F. Cooper, Biomaterials, 2008, 29, 3822-3835.

6 I. S. Yeo, Open Biomed. Eng. J., 2014, 8, 114-119.

7 F. J. van Velzen, R. Ofec, E. A. Schulten and C. M. Ten Bruggenkate, Clin. Oral Implants Res., 2015, 26, 1121-1128.

8 M. Srinivasan, L. Vazquez, P. Rieder, O. Moraguez, J. P. Bernard and U. C. Belser, Clin. Oral Implants Res., 2014, 25, 539-545.

9 W. Zhang, Z. Li, Y. Liu, D. Ye, J. Li, L. Xu, B. Wei, X. Zhang, X. Liu and X. Jiang, Int. J. Nanomed., 2012, 7, 4459-4472.

10 W. Yu, C. Qian, X. Jiang, F. Zhang and W. Weng, Colloids Surf., B, 2015, 136, 779-785.

11 A. Ballo, H. Agheli, J. Lausmaa, P. Thomsen and S. Petronis, Int. J. Nanomed., 2011, 6, 3415-3428.

12 X. Shen, Y. Hu, G. Xu, W. Chen, K. Xu, Q. Ran, P. Ma, Y. Zhang, J. Li and K. Cai, ACS Appl. Mater. Interfaces, 2014, 6, 16426-16440.

13 D. L. Fu, Q. H. Jiang, F. M. He, G. L. Yang and L. Liu, J. Zhejiang Univ., Sci., B, 2012, 13, 364-371.

14 B. S. Kim, J. S. Kim, Y. M. Park, B. Y. Choi and J. Lee, Mater. Sci. Eng., C, 2013, 33, 1554-1560.

15 N. L. Davison, J. Su, H. Yuan, J. J. van den Beucken, J. D. de Bruijn and F. Barrère-de Groot, Eur. Cells Mater., 2015, 29, 314-329.

16 L. Zhao, H. Wang, K. Huo, L. Cui, W. Zhang, H. Ni, Y. Zhang, Z. Wu and P. K. Chu, Biomaterials, 2011, 32, 5706-5716.

17 E. Anitua, L. Piñas, A. Murias, R. Prado and R. Tejero, Colloids Surf., B, 2015, 130, 173-181.

18 S. N. Nayab, F. H. Jones and I. Olsen, Biomaterials, 2005, 26, 4717-4727.

19 S. Nayab, L. Shinawi, J. Hobkirk, T. J. Tate, I. Olsen and F. H. Jones, J. Biomed. Mater. Res., 2003, 14, 991-997.

20 S. N. Nayab, F. H. Jones and I. Olsen, J. Biomed. Mater. Res., Part A, 2004, 69, 651-657.

21 R. Sawada, K. Kono, K. Isama, Y. Haishima and A. Matsuoka, J. Biomed. Mater. Res., Part A, 2013, 101, 2573-2585.

22 A. R. Ribeiro, F. Oliveira, L. C. Boldrini, P. E. Leite, P. Falagan-Lotsch, A. B. Linhares, W. F. Zambuzzi, B. Fragneaud, A. P. Campos, C. P. Gouvêa, B. S. Archanjo, C. A. Achete, E. Marcantonio Jr, L. A. Rocha and J. M. Granjeiro, Mater. Sci. Eng., C, 2015, 54, 196-206.

23 Q. Huang, X. Liu, T. A. Elkhooly, R. Zhang, Z. Shen and Q. Feng, Colloids Surf., B, 2015, 134, 169-177.

24 J. Y. Li, E. H. Pow, L. W. Zheng, L. Ma, D. L. Kwong and L. K. Cheung, Biomed Res Int. Available at, http:// www.ncbi.nlm.nih.gov/pmc/articles/PMC4317600/, DOI: $10.1155 / 2015 / 783894$.

25 Y. Huang, J. He, L. Gan, X. Liu, Y. Wu, F. Wu and Z. W. Gu, Biomed. Mater., 2014, 9, 065007.

26 A. Cunha, R. P. Renz, E. Blando, R. B. de Oliveira and R. Hübler, J. Biomed. Mater. Res., Part A, 2014, 102, 30-36.

27 A. Ballo, H. Agheli, J. Lausmaa, P. Thomsen and S. Petronis, Int. J. Nanomed., 2011, 6, 3415-3428.

28 M. Xuereb, J. Camilleri and N. J. Attard, The International Journal of Prosthodontics (IJP), 2015, 28, 51-59.
29 X. X. Wang, S. Hayakawa, K. Tsuru and A. Osaka, Biomaterials, 2002, 23, 1353-1357.

30 E. Filova, J. Fojt, M. Kryslova, H. Moravec, L. Joska and L. Bacakova, Int. J. Nanomed., 2015, 10, 7145-7163.

31 X. Ding, L. Zhou, J. Wang, Q. Zhao, X. Lin, Y. Gao, S. Li, J. Wu, M. Rong, Z. Guo, C. Lai, H. Lu and F. Jia, Int. J. Nanomed., 2015, 10, 6955-6973.

32 C. Liu, Y. Zhang, L. Wang, X. Zhang, Q. Chen and B. Wu, PLoS One, 2015, 10, e0140669.

33 S. A. Rodrigues, P. Chemin, P. P. Piaia and J. L. Ferracane, Operat. Dent., 2015, 40, 418-419.

34 B. K. Zhang and C. T. Kwok, J. Mater. Sci.: Mater. Med., 2011, 22, 2249-2259.

35 Y. S. Yu, L. S. Xie, M. H. Chen, N. Wang and H. Wang, Surf. Coat. Technol., 2015, 280, 122-128.

36 L. D. Quarles, D. A. Yohay, L. W. Lever, R. Caton and R. J. Wenstrup, J. Bone Miner. Res., 1992, 7, 683-692.

37 R. Zhou, D. Q. Wei, H. Y. Yang, W. Feng, S. Cheng, B. Q. Li, Y. M. Wang, D. C. Jia and Y. Zhou, Mater. Sci. Eng., C, 2014, 39, 186-195.

38 B. D. Choi, S. Y. Lee, S. J. Jeong, D. S. Lim, H. J. Cha, W. G. Chung and M. Jeong, J. Med. Case Rep., 2016, 14, 1241-1246.

39 S. J. Jeong and M. J. Jeong, J. Nanosci. Nanotechnol., 2016, 1, 1979-1983.

40 T. Kokubo and S. Yamaguchi, Open Biomed. Eng. J., 2015, 27, 29-41.

41 D. Buser, R. K. Schenk, S. Steinemann, J. P. Fiorellini, C. H. Fox and H. Stich, J. Biomed. Mater. Res., Part A, 1991, 25, 889-902.

42 D. D. Deligianni, N. Katsala, S. Ladas, D. Sotiropoulou, J. Amedee and Y. F. Missirlis, Biomaterials, 2001, 22, 12411251.

43 K. L. Johnson, K. Kendall and A. D. Roberts, Proc. R. Soc. London, Ser. A, 1971, 324, 301-313.

44 M. J. Dalby, N. Gadegaard, A. S. Curtis and R. O. Oreffo, Curr. Stem Cell Res. Ther., 2007, 2, 129-138.

45 L. Ferreira, J. M. Karp, L. Nobre and R. Langer, Cell Stem Cell, 2008, 3, 136-146.

46 S. Lavenus, P. Pilet, J. Guicheux, P. Weiss, G. Louarn and P. Layrolle, Acta Biomater., 2011, 7, 1525-1534.

47 K. Anselme, Biomaterials, 2000, 21, 667-681.

48 T. Miyauchi, M. Yamada, A. Yamamoto, F. Iwasa, T. Suzawa, R. Kamijo, K. Baba and T. Ogawa, Biomaterials, 2010, 31, 3827-3839.

49 X. Jiang, J. Zhao, S. Wang, X. Sun, X. Zhang, J. Chen, D. L. Kaplan and Z. Zhang, Biomaterials, 2009, 30, 45224532.

50 M. Lai, K. Cai, L. Zhao, X. Chen, Y. Hou and Z. Yang, Biomacromolecules, 2011, 12, 1097-1105.

51 Y. Hu, K. Cai, Z. Luo, Y. Zhang, L. Li, M. Lai, Y. Hou, Y. Huang, J. Li, X. Ding, B. Zhang and K. L. Sung, Biomaterials, 2012, 33, 3515-3528. 